\title{
Effect of Different Materials on the Strength Characteristics of Lightweight Concrete
}

\author{
Mudit Mishra* and Anshul Kansal \\ Department of Civil Engineering, Manav Rachna International Institute of Research and Studies, Faridabad, \\ Haryana 121004, India; mudit.fet@mriu.edu.in, anshulkansal3015@gmail.com
}

\begin{abstract}
Objectives: The present study reports the effect of various materials on the strength characteristics of lightweight concrete. Methods/findings: An evaluation has been performed to analyse the behaviour of lightweight concrete. Lightweight concrete contains cement, aggregates, and air-entraining agents. Strength characteristics of lightweight concrete are affected by the potential replacement of major ingredients through waste material and virgin raw material. Reduction in dead load with cost optimisation through lower consumption of ingredients, better thermal insulation, and better protection of the environment are major advantages of using this type of concrete. This goal is achievable through incorporation of lightweight aggregates against use of such material as fly ash, pumice stone, and geopolymers.
\end{abstract}

Keywords: Lightweight Concrete, Industrial Waste, Mechanical Properties.

\section{Introduction}

In the construction industry, concrete is the primary substance that is used; it comprises ceramic powders (cement), binders (in general water), and aggregatesfine and coarse-that in combination provide the desired levels of strength and support to the entire structure. The components of structural concrete are put into moulds of desired shape and sizes for easy operations and to provide necessary robustness and desired appearance as well. The structural concrete is of the following categories: normal mixes, standard mixes, and design mixes, and these categories are determined on the basis of mix proportions and 28-day strength in compression. As per IS 456-2000, the normal mix or ordinary concrete grades range from M5 to M20 with the 28-day compressive strength of 5 $\mathrm{MPa}$ to $20 \mathrm{MPa}$, respectively, whereas grades for standard mix range from M25 to M50 with strength levels ranging from $25 \mathrm{MPa}$ to $50 \mathrm{MPa}$. On the other hand, the grades for design mix or high-strength category range between M55 and M80 with strength ranging from $55 \mathrm{MPa}$ to $80 \mathrm{MPa} .1$ High-strength-grade concrete (often referred as highperformance concrete) shows noticeable characteristics: more strength, more workability, more density, lower permeability value, long-term durability, and resistance to anodic/acidic attacks, provided if prepared with low cement-to-water or cement-to-binder ratio ranging from 0.2 to 0.4 . Addition of highly active pozzolanic compounds like fly ash, slag, silica fumes, and so on can also result in similar characteristics. On the other hand, incorporation of these compounds and lower cementto-binder ratio also result in significant shrinkage and cracking because of change in the volume of the concrete due to drying, chemical reaction, and change in curing conditions. $\underline{2}$ In their work by $\underline{\underline{3}}$ have incorporated fibrereinforced polymer (FRP) sheet and studied the Mode-I fracture for the concrete subjected to conditions of varying temperatures and humidity levels. It was reported that FRP composites are suitable for use as reinforcement in the concrete based on several advantages, such as having stronger potential and properties that facilitate ease of renewal, repair, rehabilitation, and so on, but extreme climate conditions do have an adverse effect on these properties as the bond between FRP and concrete behave differently depending upon the level of hotness or coldness. The rise or drop in temperature results

${ }^{*}$ Author for correspondence 
in softening or tightening the adhesive, consequently resulting reduction or increase in elastic properties of the concrete, respectively, and increased susceptibility to moisture absorption. The thermal gradient can result in premature failure in adhesive-bonded FRP-concrete interface. The mechanical properties of normal concrete are not affected by coarse aggregates; however, significant variation can be observed in the case of high-strength concretes. The use of strong aggregates, for example, limestone, may result in increased compressive strength resulting from the hydration of the binder as reported by ${ }^{4}$. Furthermore, it was observed that the strength of the paste also plays a vital role besides the high-strength aggregates in the increased strength of the concrete. Another interesting fact observed is that the use of quartzite rock in the concrete does not influence the concrete's properties and that the texture of quartzite enhances the crack propagation under compressive load. The investigation carried out by $\underline{\underline{5}}$ using aggregate quarry dust as admixture and polymer fibres as reinforcement to the ordinary concrete resulted in the densification of cement paste and lower absorption values. An increase in bending strength was also observed by the addition of polymer fibres to the concrete. $\operatorname{In}^{6, Z}$ also it was reported that upon loading from a shear plane, the Poisson's ratio and tangential modulus showed a nonlinear relationship with relatively low applied load in confinement. Furthermore, shear strength decreases with the confining load and the dilation of coarse aggregates under the confining pressure of less magnitude that results in the formation of failure envelope in a nonlinear manner. As the confining load increases, the disappearance of dilation is observed and failure continues as the aggregates lead to finer elements filling the void.

The studies performed by various researchers show that the strength of concrete depends highly on the properties of the parent aggregate material that in turn results in the increase or decrease the strength of the aggregate, and consequently, that of the concrete. But at the same time, the use of such aggregates makes the concrete heavier also, requiring heavy lifting machinery or lifting means to carry out the process which ultimately affects the overall cost of construction. However, the ever-increasing industrial waste, such as fly ash, slags, foundry return sands, and so on, has led to an increased attention towards their use in the construction process through replacement of coarse/fine aggregates and where possible to replace cement as well. Using the industrial by-products in construction industry resolves main issues such as scarcity of landfilling sites and environmental pollutions by the entrapment of particulate matters. In order to make concrete economical, use of such materials with specific characteristics that affect the properties of cementitious materials should be done. This will take care of the weight of concrete and disposal of waste material.

The current article gives an overview of some of the investigations carried out by various researchers on utilising industrial by-products with concrete. Effect of replacements on strength characteristics of concrete such as compressive and splitting tensile strengths are discussed.

\section{Industrial By-products}

Industrial wastes are broadly classified into ferrous wastes like slags that are generated from iron and steel processing plants and nonferrous wastes such as fly ash, marble and granite dust, jute fibres and so on. The latter category is generally a by-product of ceramic processing plants, thermal power plants, plastic industries, and so on. All of the by-products have different grades depending on their final composition and specific physical properties such as density, specific gravity, porosity, and the amount of amorphous or crystalline solids. One such waste is spent foundry sand obtained from melting and casting plants. Such sand is thrown out once the casting is complete, as the parent properties don't remain intact after the conclusion of casting process. $\mathrm{In}^{\underline{8}}$ made a comprehensive study using spent foundry sand in concrete manufacturing, by summarising the salient points gathered from the analysis of research of various experts in the field. It was reported that spent foundry sand possess higher water absorption, lower unit weight, and higher void percentage, resulting in an increase in bleeding caused by coarse grains, and so they claimed it can be used as a substitute for regular sand and/or fly ash. Furthermore, the study reports that bonding with clay leads to reduced strength due to the water absorption in the clay compared to resin-bonded sands in the concrete mix; however, the experimentation increases the strength of concrete mixture with an increase in sand content.

Fly ash is a by-product of thermal power plants,-10; it is generated by the burning of coal in the power plants; in general, it is classified as Class $\mathrm{C}$ and Class F. Class F-type fly ash is generated by burning of bituminous or anthracite 
Table 1. Mechanical properties of various concrete mixes with fly ash as aggregate 9

\begin{tabular}{|c|c|c|c|c|c|c|c|c|}
\hline \multirow{2}{*}{$\begin{array}{l}\text { Aggregate } \\
\text { preparation } \\
\text { method }\end{array}$} & \multirow{2}{*}{$\begin{array}{l}\text { Volume of } \\
\text { fly ash }\end{array}$} & \multirow{2}{*}{$\begin{array}{l}\text { Curing } \\
\text { condition }\end{array}$} & \multicolumn{3}{|c|}{ Compressive strength (MPa) } & \multirow{2}{*}{$\begin{array}{c}\text { Splitting } \\
\text { tensile } \\
\text { strength ( } 28 \\
\text { days), MPa }\end{array}$} & \multirow{2}{*}{$\begin{array}{c}\text { Elastic } \\
\text { Modulus (28 } \\
\text { days), GPa }\end{array}$} & \multirow{2}{*}{$\begin{array}{c}\text { Flexural } \\
\text { Strength (28 } \\
\text { days), MPa }\end{array}$} \\
\hline & & & 3 days & 7 days & 28 days & & & \\
\hline \multirow[t]{6}{*}{ Cold bonded } & \multirow[t]{2}{*}{62} & Steam & 13.71 & 15.50 & 20.83 & 1.9 & 14.54 & 2.65 \\
\hline & & Hot water & 10.71 & 12.14 & 15.98 & 1.80 & 12.65 & 3.30 \\
\hline & \multirow[t]{2}{*}{50} & Steam & 16.77 & 18.95 & 25.11 & 2.20 & 17.69 & 2.94 \\
\hline & & Hot water & 13.02 & 14.77 & 19.43 & 2.10 & 15.39 & 2.26 \\
\hline & \multirow[t]{2}{*}{40} & Steam & 24.48 & 27.67 & 35.75 & 3.20 & 21.76 & 3.58 \\
\hline & & Hot water & 16.21 & 18.38 & 24.19 & 3.10 & 18.93 & 2.76 \\
\hline \multirow[t]{6}{*}{ Sintered } & \multirow[t]{2}{*}{62} & Steam & 15.22 & 17.21 & 23.12 & 2.10 & 20.13 & 4.07 \\
\hline & & Hot water & 32.79 & 35.46 & 39.97 & 2.00 & 17.71 & 3.13 \\
\hline & \multirow[t]{2}{*}{50} & Steam & 18.61 & 21.03 & 27.87 & 2.50 & 22.12 & 4.30 \\
\hline & & Hot water & 33.88 & 38.01 & 41.32 & 2.40 & 19.47 & 3.31 \\
\hline & \multirow[t]{2}{*}{40} & Steam & 27.17 & 30.71 & 39.68 & 3.60 & 22.32 & 4.36 \\
\hline & & Hot water & 36.14 & 40.55 & 44.06 & 3.50 & 19.64 & 3.36 \\
\hline
\end{tabular}

grade of coal and has pozzolanic nature, whereas Class $\mathrm{C}$ is the combustion product of lignite or sub-bituminous coal and has both pozzolanic and self-cementitious characteristics. The amount of carbon content in fly ash, which is 6\% according to ASTM C618, affects the loss of ignition (LOI) resulting in the presence of unburnt residual carbon that in turn leads to the formation of high-carbon fly ash (HCFA). HCFA cannot be used as an additive in concrete as unburnt carbon absorbs the air entrainment which is included with cement for preventing crack initiation and propagation under service load. However, it can still be used in the form of aggregates, provided it is mixed with clay and undergoes oxidation and sintering processes that remove carbon from HCFA. Table 1 shows the mechanical properties of various concrete mixes that use fly ash as aggregate.

Another alternative for the coarse and fine aggregate replacement in concrete can be quarry dust produced from the mining and extraction processes of mineral rocks. The chemical composition and physical characteristics of the quarry are not quite similar but comparable with that of river sand, which is normally preferred for construction of heavy structures. The quarry dust can be used as a replacement of sand for producing self-compacting and high-strength concrete and bricks. However, incorporation of quarry dust requires higher doses of super plasticiser to achieve the desired level of workability. $\underline{11}$
One of the major compounds that is currently under rigorous investigation is plastic waste; currently, research is going to determine the best ways to eliminate or dispose it safely in order to prevent or reduce environmental degradation caused by undisposed plastic waste. Plastic wastes are not only industrial by-products but also are a household waste. These are generally the by-products of fabric manufacture, bottle manufacturing plants, synthetic industry, electronics and electrical components manufacturing; plastic waste is difficult to destroy as the burning of plastics releases unhealthy smokes into the atmosphere and burying them underground also poses a threat to the fertility of the soil. Hence, an alternative solution is to use plastic waste in the construction industry as a replacement for core elements. Use of plastic waste such as polystyrene from the packaging industry in the concrete performs as a good heat insulator with lightweight and bulk density providing sufficient compressive strength to the structure and it has been found suitable for horizontal structures, particularly for filling $\underline{12}-\underline{14}$. Plots showing strength of concrete with plastic content are presented in Figures 1 and 2.

\section{Effect on Concrete Properties}

The properties of concrete primarily depend upon its constituents that result in a sufficient mechanical bonding between each other and prevent crack propagation under 


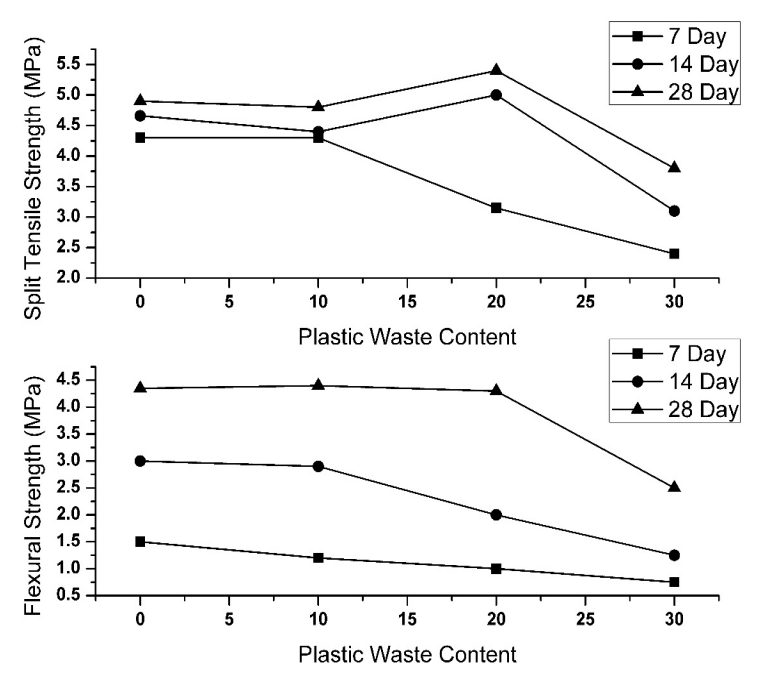

Figure 1. Plastic waste content vs strength of concrete. $\underline{12}$

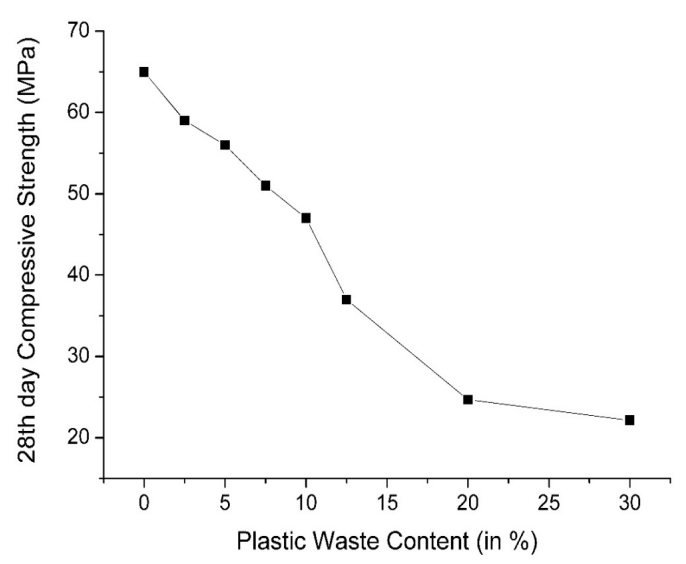

Figure 2. Plastic waste content vs compressive strength of concrete. $\underline{12}-\underline{14}$

service-load conditions. The lightweight materials used to replace core ingredients affect the properties of concrete for a range of reasons, including the pozzolanic reaction of fly ash with water when it is used as a substitute for fine aggregates or cement. The shape and size, orientation in the structure, volume of replacement, and surface characteristics of artificially prepared aggregates do have an influence on the concrete properties.

In 15 the researchers used blast furnace slag along with fly ash in varied proportions with a polymeric modifier to ensure better workability and observed that the incorporation of fly ash instead of aggregates along with modifier yielded an increased compressive strength as compared to standard concrete mix. The addition of fly ash and micro silica was proven to be effective in withstanding high temperatures ranging from $800^{\circ} \mathrm{C}$ to $1000^{\circ} \mathrm{C}$ with acceptable compressive strength; however, a considerable reduction in flexural strength was also obtained.

$\mathrm{In} 10$ the researchers employed a holding stage during the sintering process of HCFA lightweight aggregates that resulted in complete oxidation of unburnt carbon and acted as a built-in fuel leading to a decrease in sintering time. The spherical aggregates were observed to have tiny pores on the surface that had a direct effect on water absorption rate and the bonding with cement matrix. This, in turn, resulted in the infiltration of cement paste into the shell of HCFA-LWA and provided good mechanical bonding. The holding stage during the sintering process resulted in $91 \%$ compressive strength development within 7 days of curing, compared to the strength achieved after 28 days in the case of normal aggregate concrete. In another work Gomathi and Sivakumar ${ }^{9}$ used fly ash in the form of aggregates prepared by disk pelletiser in addition to bentonite as a binder and alkali activator; this resulted in the stabilised aggregate formation and increased the strength after sufficient curing. The crushing strength of the hot oven-cured aggregates has been found to be within acceptable range for fabricating lightweight concrete, which is attributed to the effective polymerisation process during the curing process. Though the decrease in concrete strength was observed when more fly ash aggregate was used, the strength was found to have increased noticeably with higher cement content.

In 11 conducted an investigation on flow, bulk density, compressive strength, and thermal conductivity of lightweight concrete by replacing $75 \%-100 \%$ of river sand with quarry dust. It was seen that for a specified water-tocement ratio the fluidity is reduced, but upon increasing the ratio there was no noticeable change in compressive strength. The observation was attributed to the reduction in the desired foam volume. Use of such higher amount of quarry dust to replace river sand resulted in increased compressive strength as well as compressive strength index when compared with the concrete prepared by using sand only. The thermal conductivity was also observed to increase slightly because of the pore formation and denser microstructure than in the case of using quarry sand; the process yielded better compactness in concrete leading to increased mechanical properties, given the additional advantageous characteristics such as water-to-cement ratio, rheological properties, and improved mechanical properties. $\underline{16}$ 
Plastic wastes generated by various industrial by-products possess low yielding strength and high compressibility as compared to other industrial by-products when brought to a particular form such as aggregate. Polystyrene, if used alone in the lightweight concrete, doesn't contribute to the density; however, it improves the thermal conductivity; on the other hand, ethylene vinyl alcohol results in increased strength and lower thermal conductivity, and this is also the case with the PVC cables from electrical wire, as reported by. $\underline{13}$ The use of plastic waste also increases the tendency of hydration of concrete resulting in lower compressive strength. $.7,18$ The increased amount of plastic waste results in reduced slump flow diameter for normal concrete, but this is acceptable in the case of self-compacting concrete. Replacement of plastic waste with regular sand results in decreased compressive strength when compared with normal design mix concrete. However, the use of plastic waste makes the concrete ductile, thereby significantly contributing to its deformation against failure and can be useful in harsh weather conditions where freezing and thawing play an important role.

The palm shells, as well as rice husk from the agricultural industry, have garnered growing attention as a substitute for aggregates for producing lightweight concrete. Though these by-products are coming into focus only for producing lightweight concrete, their strength characteristics haven't been proven to be sufficient for any kind of heavy structural applications as their compressive strength was observed to be lower than that of normal concrete mix design even with variation in water-to-binder ratio and addition of admixtures. $\underline{19}, \underline{20}$ In their investigation,, 11 observed reduced values of compressive strength; however, the splitting tensile strength, which is attributed to the porous characteristics of the oil palm shell, resulted in the formation of the spongy arrangement of lightweight aggregate and dispersion of micro cracks under tensile loading (Figure 3). The studies performed by르를 of waste glass with cement showed a decreased bulk density of the concrete. In contrast, the compressive strength was reported to increase due to the pozzolanic characteristics of glass, by replacement up to $10 \%$.

\section{Conclusions}

A thorough study of various available researches on the effect of industrial waste like fly ash, quarry dust, slag from blast furnace on properties of lightweight concrete
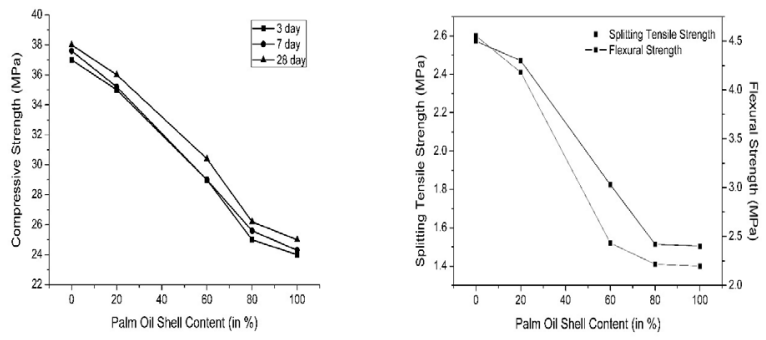

(a) Compressive strength (b) Splitting tensile and flexural strength

Figure 3. Palm oil shell vs properties of concrete. 21

was carried out and following results were drawn from the study:

i. Incorporation of fly ash in various form results in an increase in compressive strength because of the pozzolanic characteristics that consequentially trigger the bonding between cement, reinforcement, and aggregates. In contrast, the increase in volume fraction results in reduced flexural strength and thermal conductivity.

ii. Using quarry dust leads to increased compressive strength if a bigger quantity is used to replace cement, and, unlike fly ash, it can also increase flexural strength and thermal conductivity. However, the best properties are only achievable at a definite water-to-cement ratio.

iii. Industrial waste such as plastics and its different forms cannot be a good choice for use in lightweight concrete as of now given its lower compressive strength. However, further investigations can be made to find ways to improve the properties of concrete with glass used as a substitute instead of plastic.

iv. Use of agricultural waste such as oil palm shell yields a decreased level of strength and thermal properties, but in some cases with proper water-to-cement ratio it was also found to increase the strength of the concrete. More in-depth investigations can be carried out on agricultural waste, and an optimum-mix may be used as lightweight concrete.

v. The literature published so far discusses only the behaviour of concrete upon its replacement with various industrial wastes. However, more detailed investigations are indeed required to understand the phenomena behind the behaviours of the different substitutes discussed in this article. 


\section{Acknowledgements}

The authors are indebted towards the help of Accendere Knowledge Management Services Pvt. Ltd., New Delhi, India, for their support in aiding our technical understanding of the subject matter as well as in the preparation of the manuscript.

\section{References}

1. Anum I, Williams FN, Adole AM, Haruna A. Properties of different grades of concrete using mix design method. Int J Geol Agric Environ Sci. 2014;2:6-10.

2. Quangphu N, Linhua J, Jiaping L, Qian T, Tienquan D. Influence of shrinkage-reducing admixture on drying shrinkage and mechanical properties of high-performance concrete. Water Sci Eng. 2008;1(4):67-74.

3. Pizhong Q, Yingwu X. Mode-I fracture and durability of FRP-concrete bonded interfaces. Water Sci Eng. 2008;1(4):47-60.

4. Kiliç A, Atiş CD, Teymen A, Karahan O, Özcan F, Bilim $\mathrm{C}$, et al. The influence of aggregate type on the strength and abrasion resistance of high strength concrete. Cement Concrete Comp. 2008;30(4):290-96.

5. Kotwa A. Effect of selected admixtures on the properties of ordinary concrete. Procedia Engineering. 2015, 108, pp. 504-9.

6. Hanlong L, An D, Yang S. Shear behavior of coarse aggregates for dam construction under varied stress paths. Water Sci Eng. 2008;1(1):63-77.

7. Xuhua R, Jiaqing S, Nenghui B, Hongyun R. Stability analysis of concrete gravity dam on complicated foundation with multiple slide planes. Water Sci Eng. 2008;1(3):65-72.

8. Siddique R, Noumowe A. Utilization of spent foundry sand in controlled low-strength materials and concrete. Resour Conserv Recycl. 2008;53(1-2):27-35.

9. Gomathi P, Sivakumar A. Accelerated curing effects on the mechanical performance of cold bonded and sintered fly ash aggregate concrete. Constr Build Mater. 2015;77:276-87.

10. Lo TY, Cui H, Memon SA, Noguchi T. Manufacturing of sintered lightweight aggregate using high-carbon fly ash and its effect on the mechanical properties and microstructure of concrete. J Clean Prod. 2016;112:753-62.
11. Lim SK, Tan CS, Li B, Ling TC, Hossain MU, Poon CS. Utilizing high volumes quarry wastes in the production of lightweight foamed concrete. Constr Build Mater. 2017;151:441-8.

12. Manjunath BTA. Partial replacement of E-plastic waste as coarse-aggregate in concrete. Proc Environ Sci. 2016;35:731-9.

13. Gregorova V, Ledererova M, Stefunkova Z. Investigation of influence of recycled plastics from cable, ethylene vinyl acetate and polystyrene waste on lightweight concrete properties. In: Procedia engineering; 2017. P. 127-33.

14. Hama SM, Hilal NN. Fresh properties of self-compacting concrete with plastic waste as partial replacement of sand. Int J Sustain Built Environ. 2017;6(2):299-308.

15. Melichar T, Bydžovský J, Keprdová Š. Study of parameters of new polymer-cement composites after exposure to extreme temperatures. Adv Mater Res. 2014;1000:81-4.

16. Lynda AC, Kadri EH, Sebaibi Y, Soualhi H. Dune sand and pumice impact on mechanical and thermal lightweight concrete properties. Constr Build Materls. 2017;133:209-18.

17. Nursyamsi, Zebua WSB. The influence of pet plastic waste gradations as coarse aggregate towards compressive strength of light concrete. In: Procedia engineering. 2017. P. 614-9.

18. Rumšys D, Bačinskas D, Spudulis E, Meškenas A. Comparison of material properties of lightweight concrete with recycled polyethylene and expanded clay aggregates. In: Procedia engineering. 2017.P. 937-44.

19. Muthusamy K, Zamri N, Zubir MA, Kusbiantoro A, Ahmad SW. Effect of mixing ingredient on compressive strength of oil palm shell lightweight aggregate concrete containing palm oil fuel ash. In: Procedia engineering. 2015. P. 804-10.

20. Nodeh Farahani J, Shafigh P, Bin Mahmud H. Science direct production of a green lightweight aggregate concrete by incorporating high volume locally available waste materials. Proc Eng. 2017;184(184):778-83.

21. Alengaram UJ, Alamgirkabir SM. Engineering properties of oil palm shell and palm oil clinker based geopolymer concrete. Rev Téc Ing Univ Zulia. 2015;38:34-48.

22. Hooi LS, Min PJ. Potential of substituting waste glass in aerated light weight concrete. In: Procedia engineering; 2017. P. 633-9.

23. Oreshkin D, Semenov V, Rozovskaya T. Properties of lightweight extruded concrete with hollow glass microspheres. In: Procedia engineering; 2016. P. 638-43. 